\title{
Dynamic response of a large landslide during a strong earthquake
}

\author{
R. Meriggi \& M. Del Fabbro \\ Department of Georesources and Territory, Udine University, Italy
}

\begin{abstract}
This paper reports the stability analysis results of a slope, located in the northeastern Alps of the Friuli Venezia Giulia (Italy), subjected to an earthquake of equal magnitude to that which shook the area in 1976. The soil mass involved in the landslide was greater than 1 million $\mathrm{m}^{3}$ and caused heavy structural damage, especially in the village of Salars. The failure surface mostly develops inside the shale formation present below the detrital cover. The geotechnical properties have been measured by laboratory tests and geophysical investigations, accompanied by the monitoring of deep movements, water table variations and weather conditions. Soil investigations and displacement monitoring point out a generalised situation close to instability confirmed by the results of the preseismic stability analysis. Both simplified and advanced methods have been used to analyse the slope stability conditions. Dynamic slope behaviour has been analysed by means of a finite element analysis and the results have allowed the displacements, accumulated during the paroxysmic phase, to be estimated using Newmark's method; the calculated displacements have also been compared to those obtained by statistical correlations proposed by other authors. Moreover the increments of pore water pressures have been evaluated using correlations with shear stress increments along the sliding surface; these new values of pore water pressure have subsequently been used to estimate the post-seismic slope stability conditions and only a slight reduction of the safety factor was observed. This is due to high confinement pressures existing along the failure surface. The theoretical displacement accumulated in dynamic conditions has resulted in nearly twice that measured annually and may therefore cause further damage to, or the collapse of, buildings already damaged by the natural evolution of the landslide movement.
\end{abstract}

Keywords: dynamic stability analysis, safety factor, displacement. 


\section{Introduction}

The paper reports the results of stability analyses of the slope on which the village of Salars lies, in the north-eastern Alps of Friuli Venezia Giulia (Italy) (Fig. 1). The site is located on the right bank of the Margò stream and, since 1960, has been subjected to large landslide movements involving small villages situated downstream from Salars, causing damage to and the collapse of some buildings, compelling the inhabitants to abandon them and move house. In the last forty-five years major movements have occurred in the area involved and the stability situation has progressively worsened. This study therefore aimed to evaluate slope behaviour during and immediately after a seismic event equivalent, in magnitude and intensity, to the strong earthquake which struck the area in 1976. Both simplified and advanced methods have been used to perform the dynamic analysis: the former are very useful and common in professional practice, but may lead only to a rough estimate of displacements, while the latter must be used in order to obtain more realistic permanent deformations. Besides, pore water pressures, developed in the soil mass during the seismic event, depend on the size and distribution of dynamic shear stresses, which may be calculated with a good degree of accuracy by FEM analysis.

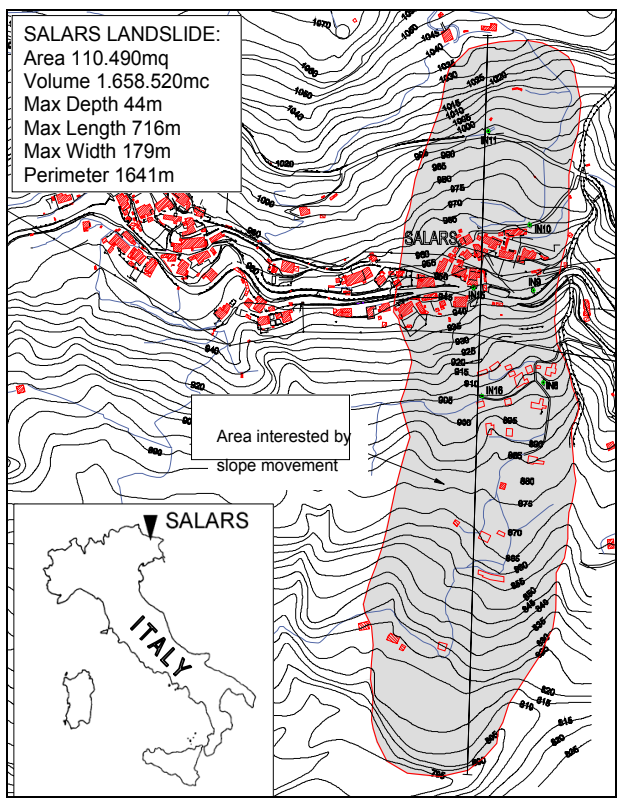

Figure 1: Location of the Salars landslide.

The lithological and geotechnical properties of the soils involved in the landslide were measured using a large number of boreholes, together with geophysical and laboratory tests; deep slope movements, groundwater table 
variations and weather conditions were monitored over a period of about four years. In particular 24 boreholes were drilled up to a depth of between $35 \mathrm{~m}$ and $75 \mathrm{~m}$, both core destruction drilling and continuous core borings with collecting of remoulded and undisturbed samples for the laboratory analysis. Lefranc and Lugeon permeability tests were performed inside the boreholes, and 20 inclinometers and 19 Casagrande piezometers subsequently installed. Several cross-hole, down-hole and VSP tests allowed the buried shapes inside the soil mass to be identified; six seismic refraction bases of $230 \mathrm{~m}$ in length were also performed. The stratigraphical section based on the information obtained from the borings is shown in Fig. 2; three different lithological units are distinguishable:

- detrital and morainic cover, sometimes with erratic blocks, of a thickness varying from one to ten metres; the cover mainly originates from alteration of the underlying shale;

- very weathered grey and light-brown shale bank of variable thickness and schistose structure;

- from compact to strongly fractured siltstone. Siltstone is mainly grey-blackish, with schistose structure and calcite veins, alternating with dark grey shale layers $50 \mathrm{~cm}$ thick.

The failure surface position and deep displacement were monitored by inclinometers from 1995 to 1999. Mean values of cumulated displacements during the observation period are between $90 \mathrm{~mm}$ and $150 \mathrm{~mm}$, with the highest value, $240 \mathrm{~mm}$, being measured by inclinometer $\mathrm{n}$. 10, located in the mid-upper part of the landslide (Fig. 2). According to the method suggested by IUGS/WGL [1], the landslide may be classified as a slow movement, with a displacement rate ranging between $22.5 \mathrm{~mm} / \mathrm{yr}$ and $37.5 \mathrm{~mm} / \mathrm{yr}$. The evolution of displacements has not undergone much modification, even after the construction of 5 drainage wells in the second half of 1996 in an attempt to stabilize the landslide.

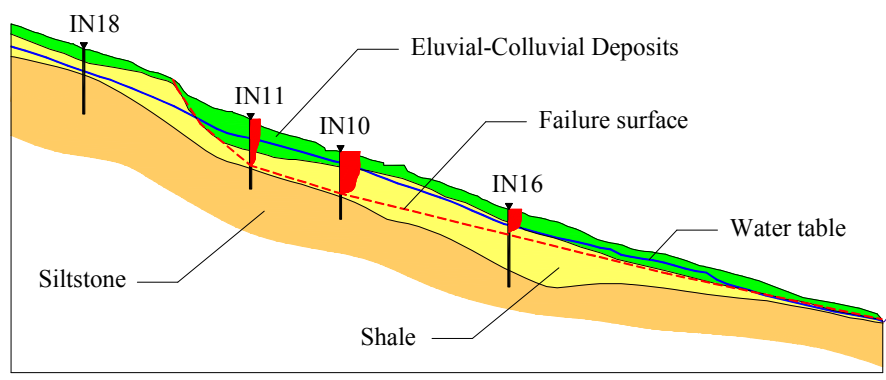

Figure 2: Stratigraphical section of the landslide soil mass.

The failure surface (Fig. 2) mainly develops inside shale and crosses the detrital cover only near the toe and the main scarp. The landslide movement is prevalently translational and develops locally at the interface with the siltstone 
bedrock. The main morphologic landslide parameters are shown in Fig. 1; they involve an instable soil mass greater than 1 million cubic meters, a length greater than $700 \mathrm{~m}$, a mean width of $170 \mathrm{~m}$ and a mean depth of $40 \mathrm{~m}$. The detrital and shale cover that forms the landslide has a wide variation of permeability, $10^{-7} \mathrm{~m} / \mathrm{sec}<\mathrm{k}<10^{-4} \mathrm{~m} / \mathrm{sec}$, even for soils which belong to the same lithotypes and present at similar depths. The piezometric measurements have pointed out that the water level remains almost constant even after heavy rains. Along the main landslide axis, the water table (Fig. 2) lies at a depth of about $10 \mathrm{~m}$ below the topographic surface near the crown, becomes deeper until about $20 \mathrm{~m}$ from the village and surfaces at the toe of the slope. Study of the monthly rainfall regime shows a remarkable difference in intensity between the rainy (April-November) and dry seasons (December-March). Mean annual rainfall is about $1510 \mathrm{~mm}$, with 112 rainy days (r.d.) per year and a mean rainfall intensity of $13.5 \mathrm{~mm} / \mathrm{r}$.d. Laboratory tests have been done on both remoulded and undisturbed samples collected from the landslide mass and these allowed material classification, plus the measurement of peak and residual shear strength by means of direct shearbox and CU triaxial tests. Shale formation and detrital cover have similar particle size and plasticity characteristics, so that it's not possible to clearly distinguish the two lithotypes. They are mostly formed by rock fragments in a sandy-siltyclayey matrix, inactive and with low plasticity. The mean values of index properties are shown in Table 1.

Table 1: $\quad$ Main geotechnical properties of analysed soils.

\begin{tabular}{|c|c|c|c|c|c|}
\hline Clay (\%) & Silt (\%) & Sand (\%) & Gravel (\%) & $\gamma_{\mathrm{d}}\left(\mathrm{kN} / \mathrm{m}^{3}\right)$ & $\gamma_{\mathrm{s}}\left(\mathrm{kN} / \mathrm{m}^{3}\right)$ \\
\hline 10 & 17 & 28 & 45 & 19.41 & 21.67 \\
\hline \hline $\mathrm{W}_{\mathrm{L}}(\%)$ & $\mathrm{W}_{\mathrm{P}}(\%)$ & PI & CF (\%) & AI & $\mathrm{e}$ \\
\hline 23.9 & 17.4 & 6.5 & 10 & 0.65 & 0.445 \\
\hline
\end{tabular}

The peak shear strength was measured with both direct shear and CU triaxial tests, and is characterized by friction angle values ranging between $22^{\circ}<\phi<35^{\circ}$ and effective cohesion values close to zero. The residual shear strength, measured after 5 back and forth travels in the direct shearbox, differs for the two formations present inside the landslide mass. The shear strength values used in the stability analysis are $\phi{ }_{\mathrm{R}}=20^{\circ}$ for the detrital cover and $\phi{ }_{\mathrm{R}}=24.5^{\circ}$ for the shale formation. Elastic characteristics of soils present in the landslide mass were obtained indirectly from the results of geophysical tests: their mean values are $\mathrm{G}_{0}=178 \mathrm{MPa}$ and $\mathrm{E}_{0}=481 \mathrm{MPa}$ for the detrital cover, while $\mathrm{G}_{0}=1336 \mathrm{MPa}$ and $\mathrm{E}_{0}=3608 \mathrm{MPa}$ have been used for shale. A value of $\mathrm{v}=0.35$ has been assumed for both formations. In order to analyse the behaviour of the landslide mass during a seismic event, a real earthquake record was utilised; this event represents the strong earthquake which shook the area on the $6^{\text {th }}$ of May 1976, with a Richter magnitude of $\mathrm{Ms}=6.4$ registered by the closest seismological station (Fig. 3). 


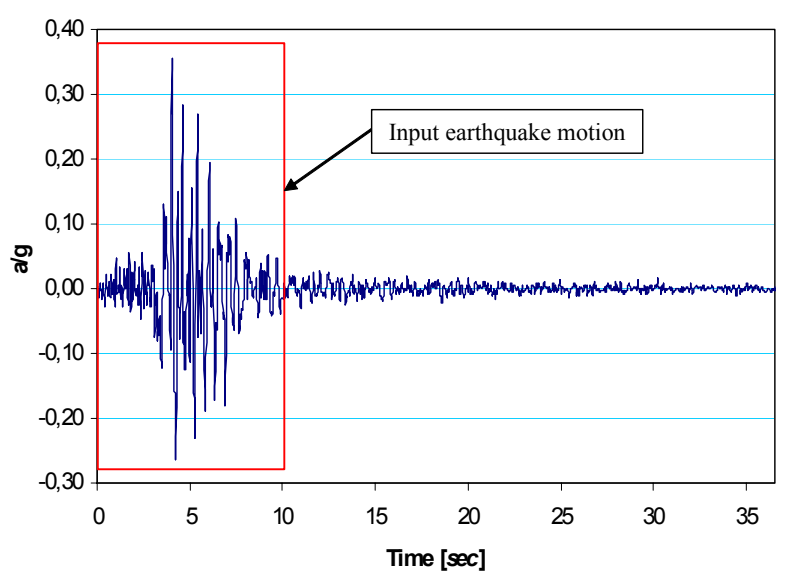

Figure 3: Design earthquake record.

The seismic wave propagated in an N-S direction. The seismic signal lasted $36.53 \mathrm{~s}$, with a peak acceleration of $0.357 \mathrm{~g}$ after $4.02 \mathrm{~s}$. The acceleration data corresponding to the first 10 seconds have been used in the dynamic analysis (Fig. 3); after that instant the seismic action produces negligible shear stresses with respect to those obtained during the maximum earthquake record intensity. The main parameters used to represent the seismic action in a synthetic form are the Arias intensity [2] and the seismic destructiveness potential factor (Saragoni [3]), equal to $\mathrm{I}_{\mathrm{A}}=0.75 \mathrm{~m} / \mathrm{s}$ and $\mathrm{P}_{\mathrm{D}}=0.062 \mathrm{~m} \cdot \mathrm{s}$ respectively (Grimaz [4]).

\section{Landslide stability analysis}

The landslide stability analysis was performed in static and dynamic conditions using both limit equilibrium and finite element methods. In particular, the evaluation of landslide behaviour during the seismic event was conducted using an uncoupled dynamic method, computing the increase in pore water pressures caused by dynamic loads separately. The discretization of the complex geometry was obtained by means of an unstructured meshing to accurately model the real aspects of the slope. The failure surface does not cross the siltstone layer and was represented in the analysis as bedrock. The boundary conditions along the interface between shale and siltstone were imposed by means of null displacements in vertical and horizontal directions, presuming the absence of differential displacements between the two materials under both dynamic and static actions. A pre-seismic analysis was done to verify the fitness of FEM to represent the slope stability conditions; as deduced by the evolution of deep and superficial displacements, these conditions are close to limit equilibrium. The state of stress and strain of the slope in static conditions were computed by an FE analysis (Geostudio [5]) using a linear elastic model in terms of effective stress, assigning shear strength and stiffness values to the previously indicated modelled materials. Pore water pressures inside the slope were evaluated introducing the 
water table position obtained by piezometric measurements in the model. The results of FEM analysis, stress-strain state inside the slope and shear stress acting along the failure surface, were elaborated again using an LE program to obtain a safety factor in static condition. The soil mass was divided into slices and a safety factor for each one was computed as a ratio between available shear force and the mobilized one, forces achieved by integration of stresses along the base of slices. The probabilistic analysis was performed with the Montecarlo method, assigning a mean residual friction angle of $\phi_{\mathrm{r}}^{\prime}=24.5^{\circ}$, a standard deviation of \pm 0.4 to the shale material and 2000 trial runs. The calculation pointed out a mean value of safety factor $\mathrm{FS}=1.054$ with an associated probability of failure $\mathrm{P}_{\mathrm{f}}=0.3 \%$; these values seem to represent the real equilibrium condition of the slope quite well. Using the same statistical variation hypotheses for the residual friction angle $\phi_{\mathrm{r}}$ of the shale, equilibrium limit stability analysis was also conducted with the Morgenstern-Price method and the main results, FS $=1.051$ and $\mathrm{P}_{\mathrm{f}}=0.3 \%$, match those obtained by FEM very well. The comparison of the mobilized shear stresses along the sliding surface, calculated with the two methods, is shown in Figs. 4(a) and 4(b).

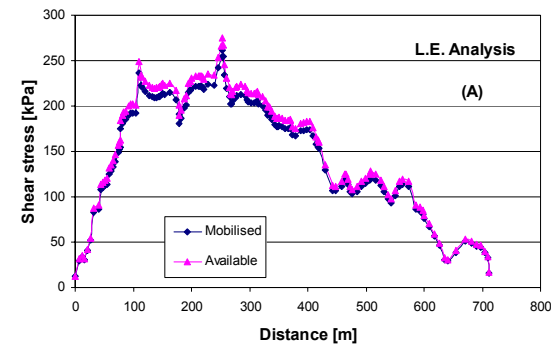

(a)

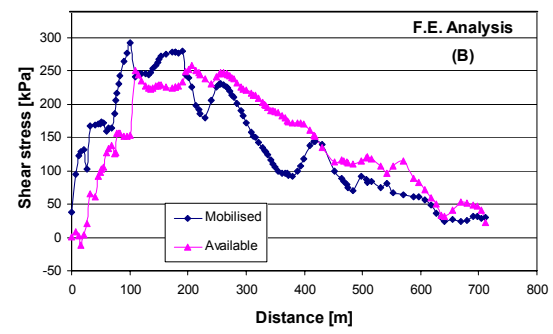

(b)

Figure 4: Shear stresses along the failure surface: (a) LE analysis, (b) FEM analysis.

Dynamic analysis was used to evaluate the stability conditions of the slope during the seismic event, permanent displacements and pore water pressure generated by cyclic shear stresses. The first step was the pre-seismic static analysis in order to evaluate stress-strain states inside the landslide mass. The next step was uncoupled advanced analysis using time-acceleration data of the first 10 seconds of the earthquake record (Fig. 3). During seismic action the soil behaviour is assumed to be non-linear elastic, assigning the initial shear modulus $\mathrm{G}_{0}$ and damping $\mathrm{D}$, and also their variation with cyclic shear strain $\gamma$. The $\mathrm{G}$ modulus reduction ratio was evaluated by means of the relationship proposed by Ishibashi and Zhang [6]:

$$
\frac{G}{G_{o}}=k \cdot\left(\sigma_{m}^{\prime}\right)^{m}
$$

where the parameters $k$ and $m$ depend on plasticity index $\mathrm{PI}=6.5$ and the response of cyclic shear strain $\gamma$. The mean normal effective stress, evaluated at step 0 , 
was assumed as $\sigma_{\mathrm{m}}^{\prime}=50 \mathrm{kPa}$ for detrital cover and $\sigma_{\mathrm{m}}^{\prime}=200 \mathrm{kPa}$ for shale. The trend of damping ratio was calculated using the equation proposed by Ishibashi and Zhang [6]:

$$
D=0.333 \frac{1+\exp \left(-0.0145 \cdot P I^{1.3}\right)}{2} \cdot\left[0.586 \cdot\left(\frac{G}{G_{o}}\right)^{2}-1.547 \frac{G}{G_{o}}+1\right]
$$

The cumulated displacements during the paroxysmal phase, calculated by means of Newmark's method [7], were computed with an LE stability program (Geostudio [5]), using the total stress state and the corresponding strain, obtained by FE analysis. At first the critical acceleration value for the landslide mass was calculated automatically and then, for each temporal step, the mean acceleration which develops along the whole failure surface. The estimate of landslide permanent displacements was obtained by means of a double integration of the excess acceleration, neglecting the values that led to counterslope movements. Critical acceleration and total accumulated displacement (Fig. 5(a)) were $\mathrm{a}_{\mathrm{c}}=0.09156 \mathrm{~m} / \mathrm{s}^{2}$ and $\mathrm{S}=0.052 \mathrm{~m}$ respectively.

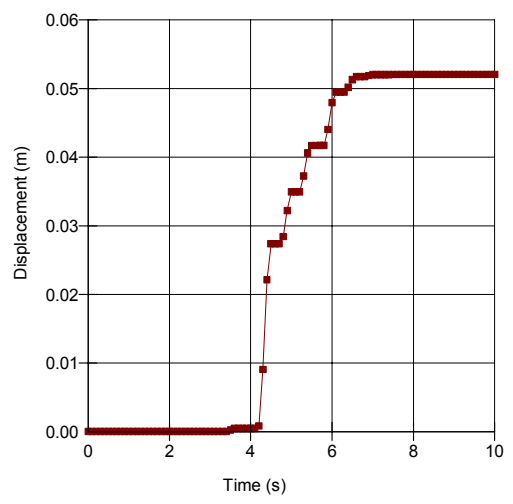

(a)

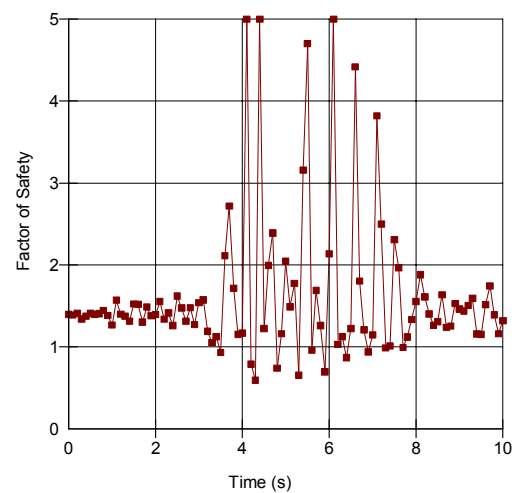

(b)

Figure 5: (a) Cumulative slope movement vs. time; (b) Safety factor vs. time.

This displacement value was compared with the one obtained by statistical correlations which use some helpful parameters to represent the intensity of seismic action, as follows:

$$
\begin{array}{ll}
S_{n}=\left(0.292+0.0762 I_{A}\right)^{2} & \text { (Luzi and Pergalani [8]) } \\
\log S_{O(\text { av) }}=1.46 \log I_{A}-6.642 a_{C} / g+1.546 & \text { (Jibson [9]) } \\
S_{0 \text { (av) }}=0.011 P_{D}{ }^{0,977}\left(a_{C} / g\right)^{-1,338} & \text { (Crespellani et al. [10]) }
\end{array}
$$


The displacements calculated for the slope subjected to the 1976 earthquake are summarised in Tab.2; the value determined with the equation proposed by Luzi and Pergalani [8] is the one closer to the dynamic analysis value.

Table 2: $\quad$ Displacements evaluated by statistical correlations.

\begin{tabular}{|c|c|}
\hline Author & Displacement (m) \\
\hline Luzi and Pergalani [8] & 0.12 \\
\hline Jibson [9] & 0.20 \\
\hline Crespellani et al. [10] & 0.34 \\
\hline
\end{tabular}

The safety factor (Fig. 5(b)) resulted as less than one only in the temporal interval where the acceleration values are maximum (from 3.5 seconds until 8 seconds approximately). The higher values of safety factor referring to the same temporal interval are caused by the elevated inertial forces that develop when the acceleration imposed on the soil mass by the earthquake is in the opposite direction to the movement. In the short time intervals where FS $>>1$, the function of displacement versus time assumes a constant value; that means no displacements have been cumulated in these periods. The mean value of safety factor associated to the whole dynamic action resulted as FS=1.318, higher than that calculated in static conditions. The evaluation diversity and hypothetical stability increase expressed by this factor depend on the different rheological models adopted for the two analyses: in the static case a linear elastic behaviour was modelled, while in the dynamic analysis the behaviour is non-linear and non-conservative. Post-seismic stability of a landslide depends on the increase of pore water pressures and on the decay of shear resistance, both phenomena related to the stress-strain state induced by the cyclic action. The earthquakeinduced pore pressure ratio was computed by equations proposed by Coumoulos and Bouckovalas [11] and Egglezos and Bouckovalas [12]:

$$
\begin{gathered}
\Delta u_{\text {max }}^{*}=\frac{\Delta u(N)}{\sigma_{v o}^{\prime}}=\frac{2}{\pi} \sin ^{-1}\left\{N_{e q}^{1 / 2 a} \cdot \sin \left[\frac{\pi}{2} \cdot \Delta u_{1}^{*}\right]\right\} \\
\Delta u_{1}^{*}=\mathrm{C}_{1} \cdot\left(\tau_{d}^{*}\right)^{\mathrm{C}_{2}} \cdot \mathrm{D}_{\mathrm{r}}^{\mathrm{C}_{3}}
\end{gathered}
$$

where $a=0.7$ (Seed and Booker [13]). To compute the induced pore pressure ratio generated during the first cycle, $\Delta u^{*}{ }_{l}$, constant numerical values proposed by Coumoulos and Bouckovalas [11] were used, $\mathrm{C}_{1}=2.6, \mathrm{C}_{2}=2.78$ and $\mathrm{C}_{3}=-4$, for relative density $\mathrm{D}_{\mathrm{r}}=0.65$, while the values of the cyclic shear stress ratio $\tau_{d}^{*}=\tau_{d} / \sigma_{v o}$ were directly obtained from the dynamic analysis results. In order to evaluate the influence on the increase of pore pressures, the number of equivalent cycles was calculated by two methods. Biondi et al. [14] have proposed the following formula:

$$
\ln \mathrm{N}_{\mathrm{eq}}=-3,8370+2.67 \cdot \ln \mathrm{M}-0.3436 \cdot \ln \mathrm{a}_{\max }
$$


that, for $\mathrm{M}=6.4$ and $\mathrm{a}_{\max }=0.357 \mathrm{~g}$, leads to a value of $\mathrm{N}_{\mathrm{eq}}=2$. Instead the graphical correlation proposed by Seed et al. [15], based only on the earthquake magnitude, indicates a more prudent mean value of $\mathrm{N}_{\mathrm{eq}}=6$. The solution of (6) with the last value of $\mathrm{N}_{\mathrm{eq}}$ provides pore pressures increments of less than $6 \mathrm{kPa}$ along the failure surface. Post-seismic stability analysis was done using the Morgerstern-Price method, changing the pore pressure increments into a water table equivalent height. In the post-seismic phase the safety factor resulted as $\mathrm{FS}^{\mathrm{ps}}=1.049$, a value which, together with a small probability failure increment $\mathrm{P}_{\mathrm{f}}=0.35 \%$, shows that slope stability is not particularly influenced by the reduction in available shear strength in this phase. For the mean earthquakeinduced pore pressure ratio $\Delta u^{*} \max =0.0041$ computed with (6) along the failure surface, the post-seismic safety factor $\mathrm{FS}^{\mathrm{ps}}$ resulted as being in good agreement with that estimated by the simplified equation proposed by Biondi \& Maugeri [16] for an infinite slope, $\mathrm{FS}^{\mathrm{ps}}=\mathrm{FS}\left(1-\Delta \mathrm{u}^{*}{ }_{\max }\right)=1.047$. At a parity of other factors, the slight increase in pore pressure generated by seismic action depends on the normalised dynamic shear stress, $\tau^{*}{ }_{\mathrm{d}}=\tau_{\mathrm{d}} / \sigma_{\text {vo }}$, which is not particularly elevated due to high confinement pressures, $\sigma^{\prime}{ }_{\text {vo }}$ acting along the failure surface.

\section{Conclusions}

The Salars landslide is caused by the high pore pressures induced by an aquifer fed by underground flows coming from the upper zone of the slope, characterized by high permeability and fissured rock mass. Even after heavy rains the piezometric level remains almost unaltered and this may explain the constant increasing trend of displacements measured by inclinometers. The two analyses performed with different methods have indicated very similar safety factors: FS=1.051 for LE method and FS=1.054 for FE method, both associated to the same probability of failure $(0.3 \%)$. The theoretic displacement accumulated by the soil mass, assimilated to a rigid block and subjected to a seismic event equivalent to the strong earthquake of 1976, resulted as about $5 \mathrm{~cm}$, nearly twice that measured annually in static condition. Such displacement may cause further damage to or collapse of the buildings already damaged by the landslide geostatic evolution. The displacements obtained by several authors' statistical correlations resulted as higher than that calculated analytically. The slight increase in pore pressure generated by dynamic action doesn't substantially alter the slope stability conditions during the post-seismic phase; in fact its safety factor is $\mathrm{FS}^{\mathrm{ps}}=1.049$, related to a slight increase in probability of failure, $\mathrm{P}_{\mathrm{f}}=0.35 \%$. It can be concluded that the stability conditions of the slope don't seem to reduce greatly on the occasion of high intensity seismic events, because of both high soil mass inertia and high confinement pressures acting on the failure surface, which prevent the development of high pore pressures.

\section{References}

[1] IUGS/WGL, A suggested method for describing the rate of movement of a landslide. IAEG Bull., 52,75-78, 1995. 
[2] Arias A., A measure of earthquake intensity. In "Seismic design for nuclear power plants”, MIT Press, Cambridge, Massachusetts, 438-468, 1970.

[3] Saragoni G.R., Response spectra and earthquake destructiveness. Proc. IV U.S. National Conference on Earthquake Engineering, Palm Springs, Florida. EERI, 35-43, 1990.

[4] Grimaz S., Caratterizzazione dei suoli di fondazione ai fini della definizione dell'azione sismica di progetto. ENAIP, Udine. Italy, 2005.

[5] Geostudio, Software Manual. GEOSLOPE Int., Calgary, Canada, 2004.

[6] Ishibashi I., Zhang X., Unified dynamic shear moduli and damping ratios of sand and clay. Soils and Foundations, 33(1), 182-191, 1993.

[7] Newmark N., Effects of earthquakes on dams and embankments. Géotechnique, 15(2), 139-160, 1965.

[8] Luzi L., Pergalani F., Analisi di stabilità di situazioni tipo connesse con fenomeni franosi in condizioni statiche e dinamiche di un'area campione. Ingegneria Sismica, anno XI, n.2, 10-32. 1996.

[9] Jibson R., Predicting earthquake-induced landslide displacements using Newmark's sliding block analysis. Transportation Research Record 1411, Transportation Research Board, Washington D.C., pp.9-17, 1994.

[10] Crespellani T., Madiai C., Vannucchi G., Earthquake destructiveness potential factor and slope stability. Géotechnique, 48(3), 411-419, 1998.

[11] Coumoulos H., Bouckovalas G.D., Analytical relationships for earthquake-induced pore pressure in sands. Research Report, National Technical University of Athens, 1996.

[12] Egglezos D.N., Bouckovalas G.D., Analytical relationships for earthquake-induced pore pressure in sand, clay and silt. Proc. of the $11^{\text {th }}$ European Conference on Earthquake Engineering, Paris, 1998.

[13] Seed H.B., Booker J.R., Stabilization of potentially liquefiable sand deposits using gravel drains. Journal of Geotechnical Engineering, ASCE, 103(7), 757-768, 1977.

[14] Biondi G., Cascone E., Maugeri M., Number of uniform stress cycles equivalent to seismic loading. Proc. $11^{\text {th }}$ Int. Conf. on Soil Dyn.\& Earth. Eng. and $3^{\text {rd }}$ Int. Conf. on Earth. Geotec. Eng., Berkeley, California, Vol.2, 705-712, 2004.

[15] Seed H.B., Idriss I.M., Makdisi F., Banerjee N., Representation of irregular stress time histories by equivalent uniform stress series in liquefaction analysis. Report n. EERC 75-29, Earthquake Engineering Research Center, University of California, Berkeley, 1975.

[16] Biondi G. \& Maugeri M., A modified Newmark type-analysis according to EC-8 requirements for seismic stability analysis of natural slopes. Proc. of the Int. Workshop "Geotechnical Evaluation and Application of the Seismic Eurocode EC8”, Athens, 2006. 